\title{
Anomic or Egoistic Suicide: Suicide Factors among Malaysian Youths
}

\author{
Jin Kuan Kok and Lee Ying Goh
}

\begin{abstract}
Suicide among the young is an acute world wide issue, and it has become an epidemic in Asia where high suicide rates in several highly populated countries have accounted for the greater part of the world's suicides. Anomic suicide has been used in describing Malaysia's suicide where less regulation is perceived by the youths in current fast changing society. This study aims to investigate young people's perspectives about death - to discover from them the possible factors giving rise to high incidences of suicide among teenagers and young adults and to possibly explain the suicidal situation in Malaysia. Two hundred and seventy youths aged 15 - 24 from various schools, colleges and hospitals in Peninsular Malaysia were recruited for this study. SPSS was used to analyze the statistic figures for frequency count and Chi-square test for independence was conducted. The findings show that youngster mostly sought help from their friends. The possible main factors for suicide revealed by the participants were: Coping with boy-girl relationships, family issues and stress from school work. A high percentage of participants indicated life was self-determined, and this revealed the changing values among the teenagers that might have contributed to the high suicide rate. Suicidal situation in Malaysia is therefore more social related. Being able to be integrated into the immediate context and society for youths is thus needed, rather than just lacking of social regulation.
\end{abstract}

Index Terms-Anomie and egoistic suicide, factors in youth suicide.

\section{INTRODUCTION}

Suicide among young is an acute worldwide issue as it has become the third leading cause of death among youth aged 10 -24 in the United States [1]. The loss of young lives who are still at their growing up stage, yet to fully emerge into adulthood is a tragedy to human mankind and it is really a heart breaking issue. Malaysia is located in South Each Asia whereby this global tragedy has become an epidemic. According to the report from world Health Organization this epidemic of suicide among young people has accounted for a greater part of the world's suicides [2].

The suicide rate among the young people is shocking in Malaysia. It keeps increasing. It was found that almost 7\% of the adolescents experienced suicide ideation and more than half of them turned their thoughts into action. The suicide rate in Malaysia, according to the National Statistics Department was as low as 1 per 100,000 suicides per year in 2003, however, national suicide registry Malaysia (NSRM)

Manuscript received November 25, 2011 ; revised December 30, 2011.

Authors are with Universiti Tunku Abdul Rahman, Kampar, Malaysia (e-mail:kokjk@utar.edu.my, lygoh@utar.edu.my). reported that there were 1.28 suicide per 100000 , in a population estimated at 27.73 million for 2008 [3]. The most recent report from NSRM (Average of 60 suicides, February $10,2011)$ computed that there were an estimated total of 425 suicide cases between January and August last year as reported on the web-based registration system. It was averaging 60 cases per month and 2 cases each day [4]. Due to difficulties in identifying a death as suicide and other issues such as claiming of insurance and dealing with family shame, the above figures could be under reporting. In actual suicide rate in Malaysia should be much higher.

Emile Durkheim (1851/1987) conceptualized suicide issues from a sociological perspective. According to his classification, there are four different types of suicide, namely altruistic suicide, anomic suicide, egoistic suicide and fatalistic suicide. Thorlindsson and Bjarnason (1998) further analyze Durkheim's initial concept, "too little integration leads to a state of loneliness and egoistic suicide; Too much integration leads to altruistic suicide when the perceived interest of the social group is set above personal interests; Under regulation causes anomic suicides of individuals lost in a chaotic universe; Over regulation results in fatalistic suicides." [5]. From the above analysis of the possible etiologies, both integration and regulation are needed. However, too much or too little can be harmful for human development. Integration cultivate social bonds and it gives a sense of belonging for individuals; whereas regulation provides guidance thus ensures safety for individuals to prevent a sense of "lost in a chaotic universe"

The Malaysian's suicide cases were analyzed by Adnan [6] from a sociological perspective. He attributes the rising suicide rate to two major factors: First, poor coping mechanism for the stresses of school life and, second, the lack of a programme to promote good mental health in the country. His perspective and description of Malaysia's suicide trend among the young people was similar to Durkheim's "Anomic" suicide, which refer to the lack of regulation among the young people. Adnan highlighted risks factor such as instability in society, the absence of family/religious protecting factors that have contributed to the rising rate of suicides cases in Malaysia. It seems logical that a sudden removal of excessive regulation or control as a result of social change will give rise to anomic behaviours.

This paper argues that suicide as a global social issue may be more complicated than expected. A linear equation or a simplistic classification of etiology may not be sufficient to pin down the causal factors of suicide. As a result of globalization, young people in Malaysia are no longer living in a closed community that can be immunized the globalized effects of feeling lost or feeling chaotic. As individuals are 
developed in a context which operates within various layers such as microsystem (refers to immediate family system), exosystem (schools system and community), exosystem (systems within systems) and macrosystem (a larger cultural system) Regulations may provide safety or security so that young people knows the guidelines about what to do and how to conduct their lives in the community. However, sense of belonging, being able to integrate into the society is equally important as it was found that family integration and parental regulation bring similar impact on youth's suicidal ideation and behaviour [5].

\section{Methodology}

A total of 270 students comprised of 127 males and 143 females aged from 15 to 24 from different parts of urban west Malaysia were recruited. The participants were from different government secondary schools and university campus across different regions in Peninsular Malaysia. A questionnaire was designed to find out their perceptions of death, and if they were prepared to discuss their views on the reasons for suicide among youth.

Permission for the study was obtained from the gate keepers of relevant authorities in the various organizations taking part, who were the principals of secondary schools and administrative authorities from local universities. The participants were informed on their right to withdraw from the study if they felt the questions were intrusive or difficult to answer. Sensitivity and confidentiality were also noted and participants were informed that only group data would be used for publication and no personal information, nor the name of their schools or organization would be revealed. Token of appreciations were given to participants who had completed the whole questionnaire.

TABLE I: GENDER AND AGE OF PARTICIPANTS

\begin{tabular}{lll}
\hline Gender & & Frequency \\
\hline Male & Below 18 & 95 \\
& 18 and above & 32 \\
& Total & 127 \\
Female & Below 18 & 86 \\
& 18 and above & 57 \\
& Total & 143 \\
\hline
\end{tabular}

Fig. 1. Ethnic groups of participants

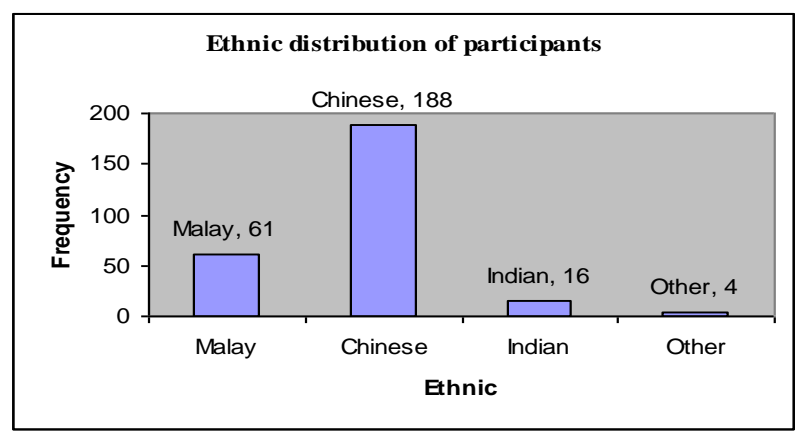

There were 181 students below the age of 18 , and 89 students were aged 18 and above.

\section{FINDINGS}

The findings suggest that most students are open to discussion about the topic of death. They mostly discuss it with their friends. Males are likely to attribute the reason for suicide to boy-girl relationships; this is similar across all ethnic groups. As for other possible reasons for suicide, more Chinese students thought the stress of school work was the most likely cause. Malay students put more emphasis on family issues.

\section{A. Open to Discussion on the Topic of Death}

Approximately $58 \% \quad(n=34)$ of Malay students, $74 \%$ $(n=139)$ of Chinese students, and 63\% (n=10) Indian students will not avoid the discussion of death in a conversation. Friends are the resource people which whom they discussed this sensitive issue.

Fig. 2 shows the answers to the question "who would you talk to" on the topic of death. Friends and family are the two main source of communication on this topic. More participants chose to talk with their friends rather than with family members.

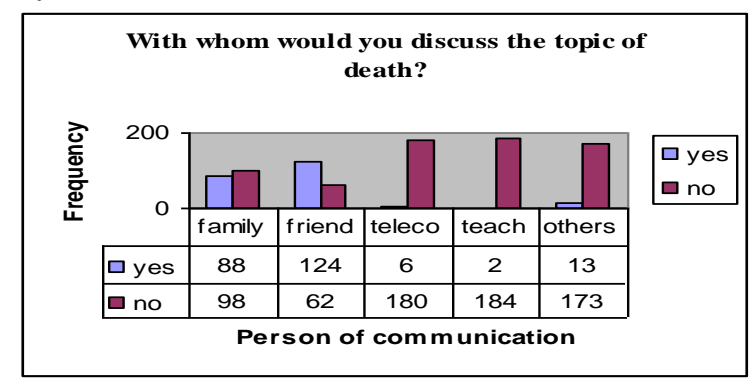

Fig. 2. With whom teens discuss the topic of death

\section{B. Possible Factors for Teenage Suicide}

Three sources of stress that might have been caused for suicide for the young people were identified, namely boy-girl relationships, family issues and school work.

Fig. 3. Male participants' views on the possible factors in teenage suicide

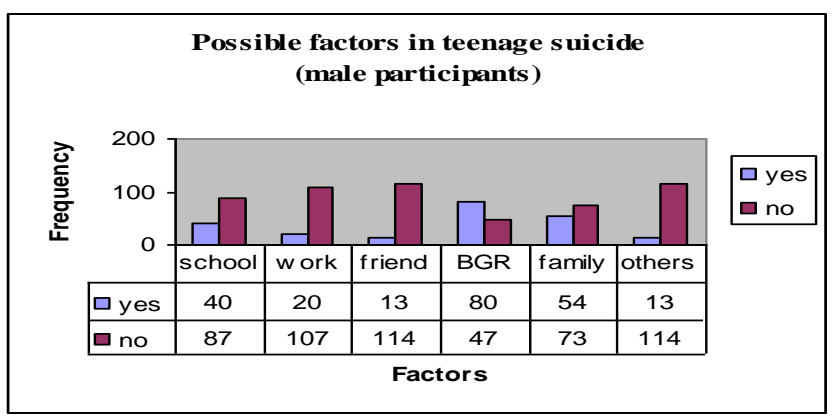

Boy-girl relationships ranked the highest for the possible reasons for suicide for both the male and female students.

Fig. 4. Female participants' views on the possible factors in teenage suicide

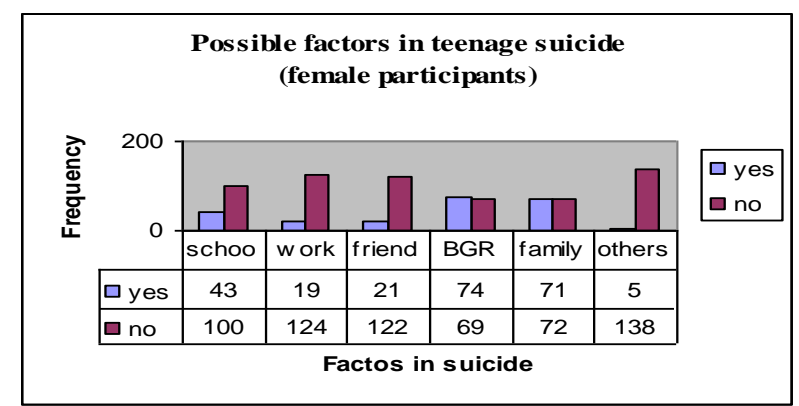


Eighty out of $127(63 \%)$ of male participants and 74 out for $143(52 \%)$ female participant stated BGR as the possible reason for suicide. More male participants than female participants think BGR issues contribute to suicide.

Seventy one (around 50\%) females stated family issues as a possible reason for suicide. Male students' answers were comparatively lower on family issues. Only 54 (42.5\%) of male students stated family issues as a possible suicide reason.

Fig. 5. Family issues as a main factor in teenage suicide

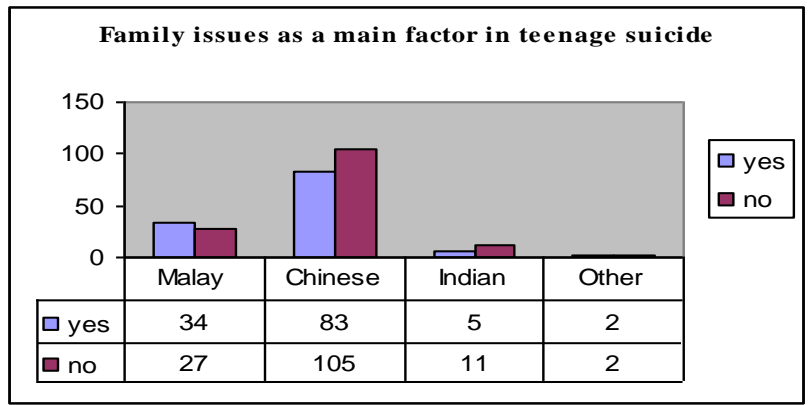

Thirty four out of 61 of Malay participants (55.7\%) stated family issues as a reason for suicide, whereas the percentage of Chinese and Indian participants are lower. 83 out of 188 of Chinese $(44.1 \%)$ and 5 out of 11 Indian participants $(31.2 \%)$ stated family issues.

Fig. 6. School work as a main factor in teenage suicide

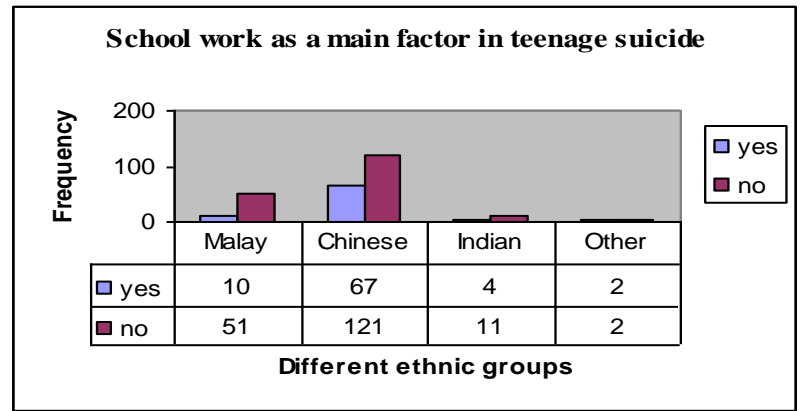

From the above tables: Among the three major ethnic groups, students from the Chinese community mentioned school work as the source of most stress, they also gave it as the main cause in suicide. The frequency and percentages were as follows: 67 out of $188(35.6 \%)$ for Chinese, 4 out of $12(25 \%)$ for Indians and 10 out of 61 for Malays (16.4\%).

The Chi-square test for independence was run and the result showed that there was a significant association between the ethnicity (Chinese vs non-Chinese) and school work as a reason for suicide cases (Yes vs No), $x^{2}(1, n=269)$ $=6.696, p=0.01$. More Chinese thought that school work is a main cause in suicide than non-Chinese (35.6\% vs. $19.8 \%$ ), whereas more non-Chinese thought that school work is not main cause in suicide compared to Chinese (80.2\% vs. $64.4 \%)$.

\section{Who Determines Life?}

All the participants regardless of religious background stated that life was determined by the individual, rather than by others or the creator of the universe. When asked "Who determine life", most of the participants, the answers were as follows:
Fig. 7. Life is determined by myself: Response from different ethnic groups

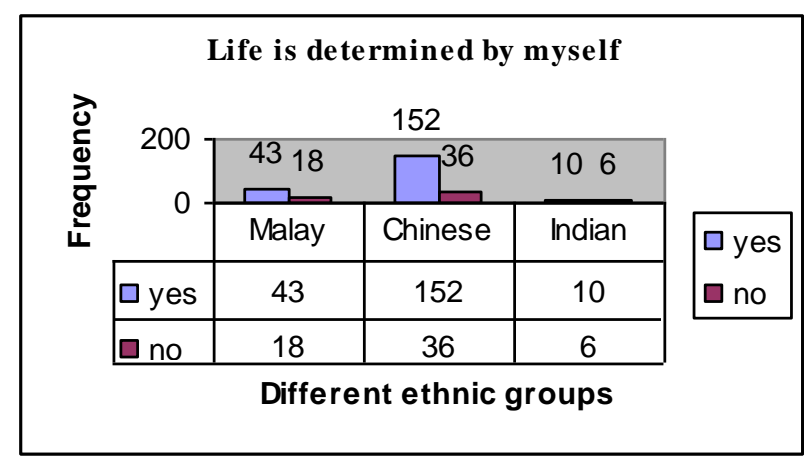

Fig. 8. Life is determined by other people: Response from different ethnic groups

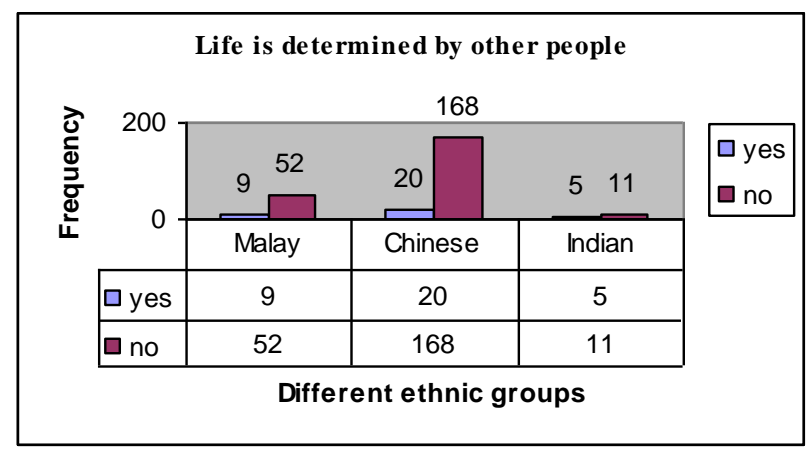

Fig. 9. Life is determined by the creator: Response from different ethnic groups

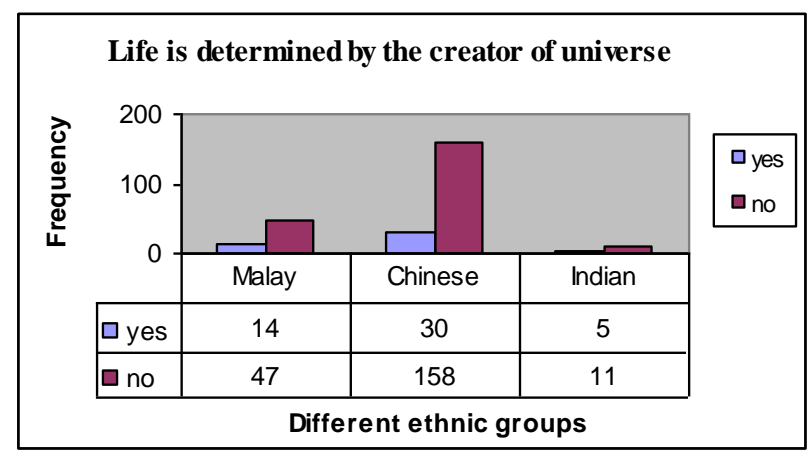

\section{DISCUSSION}

This study discovers three sources of stress identified by participants as possible factors in teenage suicide: boy-girl relationships ranked the highest, followed by dealing with family issues and stress from school work. The finding shows that young people will not avoid the topic of death. They will seek helps from friends and teachers were people of last resource.

Coping with boy-girl relationship is common for young people at this stage of development. However it can present enormous stress especially for male participants when emotional support is not available especially when the relationship does not work. It is particularly true and has presented as a potential source of stress for male participants as shown in this study. Durkheim's suicide theory [6] has depicted males as always more vulnerable in dealing with relationship hence their risk of suicide is considerably higher. The findings seem to be in line with Durkheim's postulation as the male students are more emotionally vulnerable. High 
percentage of male participants indicated that a broken relationship as a factors for suicide. There are some gender differences found in this study and it is supported by other literature that women tend to use suicide as 'cry for help' [7]. Men would normally use drastic action when come to suicide behaviours. It could be explained by the male reluctance to share their personal problems with others when they experience emotional disturbances. Instead, they opt for serious suicide action.

The second factor identified in suicide was family issues. Families are bound to face a lot of changes as a result of social change. The society nowadays is getting increasingly competitive, fast-paced, full of uncertainty, rapid change, insecurity and risk taking. Most families are dual income family and parents are busy with work. Hence children are pretty much left on their own. Adnan [6] attributes suicide to an unstable context, in which our youths are growing up, and which includes a lot of risk factors. Some of those factors identified in this study were the stress of coping with boy-girl relationships and school work. Moreover, the family itself becomes a source of stress for the young people. This seems to confirm the Adnan's postulation of external environment factors, especially changing of family setting and traditional values. Durkheim might describe those factors which arise from a state of dissatisfaction due to external stress that influence the family settings as anomic suicide.

The third factor in suicide is school environment. Young people spend most of their time in school, and school is supposed a place to help in their development. Instead of cultivating positive attitude towards life, it is always a place of stress for most students. The findings from this study reveal that more students cited stress from school work as the main factor in teenage suicide. This is supported in the literature that education is most valued in traditional Chinese families and can be traced back from Chinese Confucian beliefs [8], Malaysian Chinese families are no exception. As stated in our previous findings, most Chinese parents would expect high academic performance from their children and children from such families rarely want to disappoint their parent due to the Confucian teaching of filial piety [9]. In return, most Chinese participants cited school work as main contributing factor to suicide. Will Durkheim describe school stress factor as anomic?

We could explain the suicide cases in Malaysia according to the framework initialed by Durkheim's theory and further supported by Adnan's postulation. Meaning, it was due to the lack of regulation that our young people feel that they are not able to cope with boy-girl relationships, the stress coming from educational system and family stress. However, the reality of suicide as a global social issue could be more complicated. To look it from another perspective, it is equally logical if we explain it in another way: It was due to the lack of social bonds that our young people were not able to cope with boy-girl relationships, feel being lost in an increasingly stressful school environment and not able to be integrated in the current family and social system. It seems that "Anomic" suicide is not sufficient to explain the suicide cases among young people in Malaysia.

It is supported by the literature that family attachment reduces the possibility of attempted suicide among the young.
Only young people who are raised by warm and caring parents are more able to have felt the warmth and care, thus less likely to yield to anomie and suicidality [5]. So, it is not only the lack of regulations, as regulations without warmth and care will breed hatred. Regulations normally refer to rules and controls. It is important not to minimize the complexity of the modern society. This modern society describe by Bauman as liquid modernity which is "slippery, shifty, evasive" [10]. Coping with modern lives which are full of uncertainties, fears and potentially chaotic situation, it is bound to feel lost and lack of sense of belonging. It is both the family integration and parental warm and firm guidance that could save our young people from having suicide ideation. With the guidance of warmth and caring parents, family will serve as a resource for young people instead of a source of stress that lead to suicide behaviours. Nevertheless, as a result of current social changes and economic forces, not only fathers, but Malaysian mothers have been coerced into going to work in order to earn a better living [11], ensuing this protective factors may no longer exist.

Similar analysis applies to the school integration and social integration. When students being constantly failed by a school system; or as a family member who do not feel the warmth and care of a family; or as a member in the society who are not able to adapt to the societal change, the risk factors will be there. There will be no sense of belonging, self-image and self pride will be under attacked, and it will definitely affect their meaning in life.

A high percentage of participants, regardless of different ethnic groups, indicated that "Life is determined by self" instead of "by others". Does it indicate that our young people are more self-focus? Does it mean that the young people nowadays perceived they should be in control whereas in reality they are not in control. However, they want to be in control of their lives. The findings of this result may indicate that young people are increasingly reacting with dissatisfaction to the way they are regulated by society, such as the school system and the societal changes.

It was certainly not entirely due to the lack of regulation, but may also due to the lack of integration into this forever and increasingly changing values in the society. Young people experience lack of integration into the school, relationship, community or society they are living. The lack of control in their own lives causes them to feel insufficient and unable to cope when faced with uncertainties. This lack of integration into the environment where the individuals are located should be classified as "Egoistic Suicide" according to Durkheim's definition. However, it will be too simplistic to draw such conclusion. Firstly, suicide as a tragic social issue is certainly more diffuse and more complicated than such a scientific four dimensions theoretical framework could explain. Secondly, this is an increasingly individualized society, the need to be one self and the need to feel belong to the society are co-existing.

This phenomenon also shows that the values of collectivism are increasingly changing to individualistic ones. This fading away of traditional protective factors such as family, collectivism and religious norms are the immediate eco-systemic environments in which our young people are living nowadays. These findings are inline with Adnam's 
perspective that the weakening of collectivism values no longer serve as protecting factors that shield our young from ending their lives once they feel there is an absence of meaning in their lives. Therefore they are able to make decision to end their lives when they are not able to cope.

One of the positive discoveries from this study is the self-focus individuals are very much in needs of friendships.

Friendship and relationship are important for young people. It is evident in the findings that friends are the people most relied upon by the young people in times of need. Hence, developing peer support leaders in the school counselling programme could be effective in reducing suicide rates among the young. Mentoring and coaching by peer support leaders could be effective [11] as peer support programmes are found to be helpful in providing positive influences in the areas of academic and non-academic situations. Peers have a greater impact on their fellow pupils in that they serve as guides and role models. Also, working towards strengthening family ties with our young people in order to be able to offer help when needs arise is important.

\section{CONCLUSION}

Suicide as a social pathology requires preventive measures in the social context in which suicidal individuals are located. . Anomic or Egoistic? There is no simple answer to this question. This paper reveals the perspective of young people on the issues of suicide and death. Various possible causes for suicide were identified by the participants. It is hoped that further investigation could be carried out to better understand our young people from their perspectives, and the numbers of tragedies among suicidally unhappy young people might be reduced.

\section{REFERENCE}

[1] K. M. Lubell, S. R. Kegler, A. E. Crosby, and D. Karch, "Suicide trends among youths and young adults aged 10--24 years - United States, 1990-2004," Division of Violence Prevention, National Center for Injury Prevention and Control, vol. 56, pp. 905-908, Sep. 2007.

[2] H. Hendin, "Introduction: Suicide and suicide prevention in Asia," World Health Organization, Department of Mental Health and Substance Abuse, 2008.

[3] Ministry of health malaysia, clinical research centre, national suicide registry malaysia (NSRM), (2009). The Annual Report of the
National Suicide Registry Malaysia (NSRM) 2008. Retrieved from http://www.nsrm.gov.my/pdf/NSRM_report2008.pdf.

[4] Suicide figures may be higher, The Stars, Retrieved from http://www.thestars.com.my. February 10, 2011.

[5] T. Thorlindsson and T. Bjarnason, "Modeling durkheim on the micro level: A study of youth suicidality," American Sociological Review, vol. 63, no.1, pp. 94-110, 1998.

[6] Wong. Interview with Adnan. The Stars. Retrieved from http://www.thestars.com.my. February 10, 2011.

[7] J. Langhinrichsen-Rohling, J. Friend, and A. Powell. Adolescent suicide, gender, and culture: A rate and risk factor analysis. Aggression and Violent Behavior, 14(5), 402-414, 2009.

[8] S. Jimerson. (n.d.). Adolescent development: Current issues. Retrieved from http://education.indiana.edu/cas/adol/adol.html, on 30 May 2011.

[9] J. K. Kok, C. C. Gan, and L. Y. Goh. Youths talk about death: Causes for suicide. International Journal of Social Science and humanity, 1(2), 145-149, 2011.

[10] Z. Bauman. Liquid Modernity. Cambridge: Polity, 2004.

[11] J. Talib. Effects of parents' work conditions on children's school achievement: A study of dual-earner families. International Review of Business Research Papers, 5(3), 170-178, 2009

[12] N. N. SinghSingh, J. P. Leung, and A. N. Singh. International perspectives on child and adolescent mental health. London, UK: Elsevier, 2000.

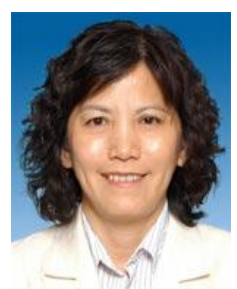

Dr Kok Jin Kuan was born in Malaysia. BA in Chinese Literature from National Taiwan University, Master in Education, specilized in Guidance and Counselling, Doctorate degree in Education, both postgraduate degrees from Durham University, England, UK. Her Present professional occupation: Assistant Professor,Department of Psychology and Counselling, Faculty of Arts and Social Science, Universiti Tunku Abdul Rahman.

Her research interests include. She is specialized in using a qualitative research methodology approach under constructivist and interpretative mode relate to the areas of social trends, counseling, education, narratology studies, and cultural studies.

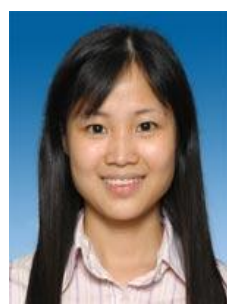

Second L. Y. Goh. Goh was born in Penang, Malaysia. She is currently pursuing her Master in Philosophy (Social Science) in Universiti Tunku Abdul Rahman. She had been participating in a Special Needs Summer Camp that organized by YMCA as Head Counselor, at Eagle Springs, Pennsylvania, in May to September 2004. She had also worked as Practical Counselor in Hospital Kuala Lumpur during her industrial attachment upon completion her first degree in 2006. With the experiences in counseling area and qualification in psychology degree, she is currently working as an academician while completing her master. Recent conferences attended were ICHSC 2011 and ARUPS $3^{\text {rd }}$ Congress 2010, both held in KL. Her areas of interest include parenting, youth development, and suicide related studies. 